\title{
Change in seismicity beneath the Tokyo metropolitan area due to the 2011 off the Pacific coast of Tohoku Earthquake
}

\author{
Takeo Ishibe, Kunihiko Shimazaki, Kenji Satake, and Hiroshi Tsuruoka \\ Earthquake Research Institute, the University of Tokyo, 1-1-1 Yayoi, Bunkyo-ku, Tokyo 113-0032, Japan
}

(Received April 8, 2011; Revised May 28, 2011; Accepted June 2, 2011; Online published September 27, 2011)

\begin{abstract}
Static changes in the Coulomb Failure Function $(\triangle \mathrm{CFF})$ forecast an increase in seismicity in and around the Tokyo metropolis after the 2011 off the Pacific coast of Tohoku Earthquake (magnitude 9.0). Among the 30,694 previous events in this region with various depth and focal mechanism, almost 19,000 indicate a significant increase of the $\triangle \mathrm{CFF}$, while less than 6,000 indicate a significant decrease. An increase in seismicity is predicted in southwestern Ibaraki and northern Chiba prefectures where intermediate-depth earthquakes occur, and in the shallow crust of the Izu and Hakone regions. A comparison of seismicity before and after the 2011 event reveals that the seismicity in the above regions indeed increased as predicted from the $\triangle \mathrm{CFF}$.
\end{abstract}

Key words: 2011 off the Pacific coast of Tohoku Earthquake, static change in the Coulomb Failure Function $(\triangle \mathrm{CFF})$, Tokyo metropolitan area, seismicity.

\section{Introduction}

On March 11, 2011, a giant interplate earthquake with magnitude $(M)$ 9.0, which was named the 2011 off the Pacific coast of Tohoku Earthquake by the Japan Meteorological Agency (JMA), struck Japan and caused a huge tsunami along the coast of the Japanese Islands. This earthquake, which we will call the Tohoku-oki earthquake for simplicity, was the largest in Japan since the start of modern instrumental observation. It was accompanied by active aftershocks in and around the source region and also by two damaging shallow crustal earthquakes more than $400 \mathrm{~km}$ away from the epicenter: an earthquake near the boundary between Nagano and Niigata prefectures on March 12 $(M$ 6.7) and another in the eastern part of Shizuoka prefecture on March 15 (M 6.4). This suggests that the Tohokuoki earthquake probably caused seismicity rate changes and may trigger large earthquakes in surrounding regions.

The metropolis of Tokyo is located $300 \mathrm{~km}$ away from the epicenter of the Tohoku-oki earthquake, and is situated in a high seismicity region, called the Kanto region, where earthquakes with various focal mechanisms have occurred because of its complex tectonics; the Pacific plate (PAC) is subducting from the East, and Philippine Sea plate (PHS) is subducting from the South beneath the Kanto region (Fig. 1). It is very likely that some of these earthquakes may fit the type of focal mechanism that is effectively induced by the Tohoku-oki earthquake.

Furthermore, the probability of a large $(M \sim 7)$ earthquake in the Kanto region is high; the Earthquake Research Committee (2004) calculated the probability of earthquake occurrence during the next 30 years as $70 \%$, based on five

Copyright (C) The Society of Geomagnetism and Earth, Planetary and Space Sciences (SGEPSS); The Seismological Society of Japan; The Volcanological Society of Japan; The Geodetic Society of Japan; The Japanese Society for Planetary Sciences; TERRAPUB.

doi:10.5047/eps.2011.06.001
$M \sim 7$ earthquakes since 1885 (Ishibe et al., 2009a, b). The Japanese government estimates up to 11,000 fatalities and economic losses of 112 trillion yen (about 1.3 trillion US\$) if a large interplate earthquake (M 7.3) were to occur in northern Tokyo Bay.

This paper examines whether or not the seismicity increased in the Kanto region due to the great Tohokuoki earthquake by calculating the static changes in the Coulomb Failure Function ( $\triangle \mathrm{CFF}$ ) (e.g., Stein et al., 1992; Reasenberg and Simpson, 1992; Toda et al., 1998) for 30,694 previously observed receiver focal mechanisms. The $\Delta \mathrm{CFF}$ is defined as $\Delta \mathrm{CFF}=\Delta \tau-\mu^{\prime} \Delta \sigma$, where $\Delta \tau$ is the shear stress changes resolved on a given failure plane (defined as positive in the fault slip direction), $\Delta \sigma$ is the normal stress changes (defined as positive in the compressive direction), and $\mu^{\prime}$ is the effective coefficient of friction. Positive $\triangle \mathrm{CFF}$ values promote failures; negative values suppress failures.

\section{Method and Data}

We calculated the $\triangle \mathrm{CFF}$ for receiver faults estimated from focal mechanism solutions of the past events because various types of earthquakes occur in the Kanto region. Utilizing the available focal mechanisms of past earthquakes as receiver faults proved to be effective for estimating $\triangle \mathrm{CFF}$ (e.g., Imanishi et al., 2006; Toda, 2008; Ishibe et al., 2011). In calculating $\triangle \mathrm{CFF}$, we assumed an elastic half-space, an apparent coefficient of friction of 0.4 , a shear modulus of $40 \mathrm{GPa}$, and a Poisson's ratio of 0.25 .

We excluded small and large absolute values of $\triangle \mathrm{CFF}$. For a small absolute value, the sign can easily reverse due to errors in hypocentral locations and focal mechanisms; hence we excluded absolute $\triangle \mathrm{CFF}$ values less than 0.1 bars, the minimum threshold commonly associated with static stress triggering (e.g., Hardebeck et al., 1998). Extremely high absolute $\triangle \mathrm{CFF}$ values $(|\Delta \mathrm{CFF}| \geq 15$ bars $)$ obtained 


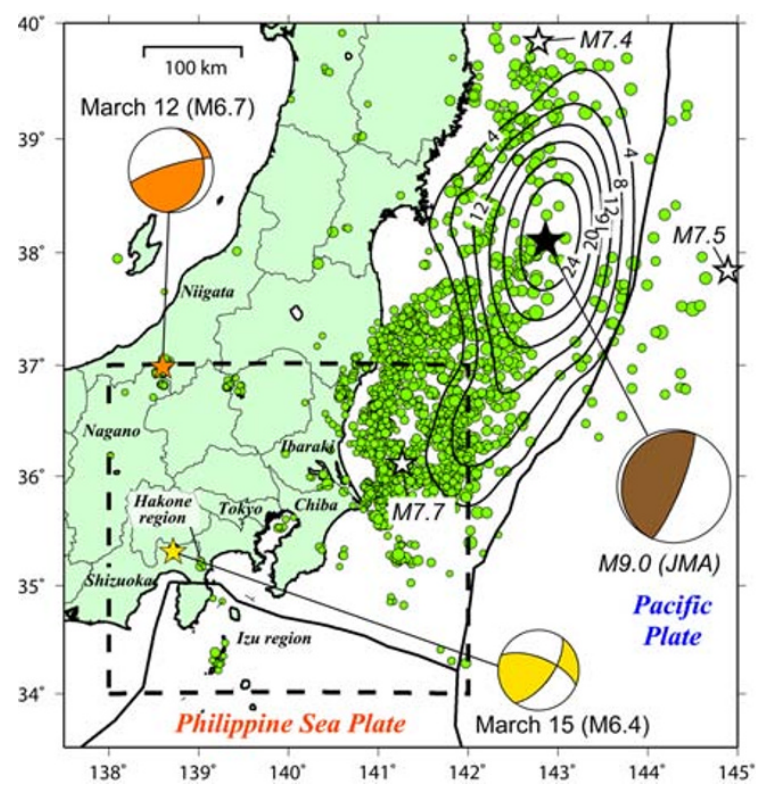

Fig. 1. Variable slip model of the Tohoku-oki Earthquake (black contour) based on continuous Global Positioning System (GPS) observation (Ozawa, personal communication). The black and white stars indicate the epicenters of the mainshock ( $M 9.0)$, and large aftershocks $(M \geq 7.0)$ that occurred within 40 minutes. GPS observation data including this period was used to estimate coseismic displacement. The orange and yellow stars indicate the epicenters of the earthquake near the boundary between Nagano and Niigata prefectures of March 12 ( $M$ 6.7), and the Eastern Shizuoka earthquake of March 15 (M 6.4) from the JMA PDE catalog. The focal mechanisms are based on JMA. The green circles indicate the epicenters of earthquakes occurring within seven days after the mainshock $(M \geq 3.0$, depth $\leq 100 \mathrm{~km})$. The dashed-rectangle region is the target region where the $\triangle \mathrm{CFF}$ values were calculated. The thin line indicates the boundary between prefectures.

near the source fault were also excluded because these may have large uncertainties caused by simplified source geometry and/or slip distribution.

For the source fault, a variable slip model of the Tohokuoki earthquake (Ozawa, personal communication; Fig. 1), based on continuous Global Positioning System (GPS) observation, was used to calculate $\triangle \mathrm{CFF}$. As the receiver faults, we used the 30,694 focal mechanism solutions determined from the initial motion by the National Research Institute for Earth Science and Disaster Prevention (NIED) from July 1979 to July 2003 (Matsumura and Observation and Research Group of Crustal Activities in the KantoTokai District, 2002). Because we do not know which of the two nodal planes an actual receiver fault is on, we repeated our analysis for the first and second nodal planes in their catalog. The Preliminary Determined Earthquake (PDE) catalog from February 1, 2011, to April 1, 2011, provided by JMA on April 2 was used to examine whether or not the forecast seismicity changes actually took place. We also used the TSEIS visualization program package (Tsuruoka, 1998) for the study of hypocenter data.

\section{Result and Discussion}

Among the past earthquakes we examined, those with positive $\triangle \mathrm{CFF}$ values outnumbered those with negative values. For the entire data set, there were 18,790 (1st nodal

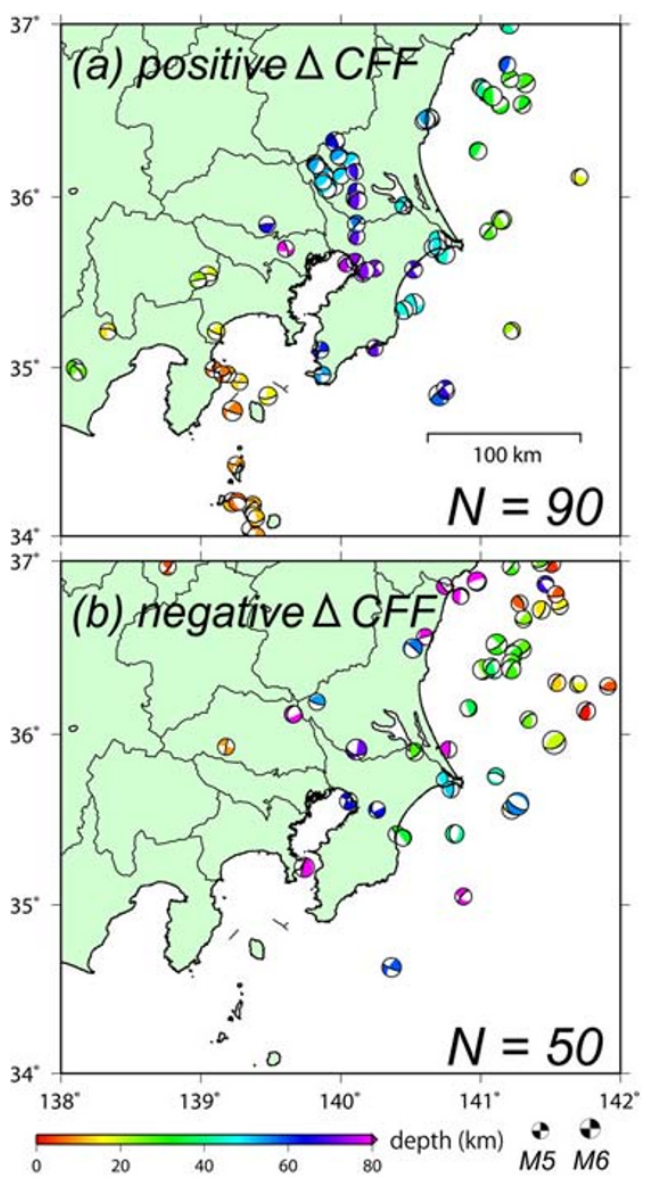

Fig. 2. (a) Focal mechanism distribution of earthquakes with positive $\Delta$ CFF $(M \geq 5.0$, depth $\leq 100 \mathrm{~km})$. The black lines indicate the nodal planes on which we have resolved $\triangle \mathrm{CFF}$. (b) Focal mechanism distribution of earthquakes with negative $\Delta \mathrm{CFF}(M \geq 5.0$, depth $\leq$ $100 \mathrm{~km})$.

plane)/18,828 (2nd nodal plane) earthquakes with positive $\triangle \mathrm{CFF}$, and 5,677 (1st nodal plane)/5,850 (2nd nodal plane) with negative $\triangle \mathrm{CFF}$. This suggests that seismicity in the Kanto region will increase as long as earthquakes with the same focal mechanisms continue to occur. Since the ratios of the number of earthquakes with positive $\triangle \mathrm{CFF}$ to the number with negative $\triangle \mathrm{CFF}$ are almost identical for both the magnitude thresholds and nodal planes (Table 1), the results for the first nodal plane will be illustrated in the figures.

The increase in seismicity does not necessarily mean that all of the regions will become active. Earthquakes at some depths with some focal mechanisms have positive $\triangle \mathrm{CFF}$ values while others have negative values (Fig. 2). The positive events (Fig. 2(a)) are concentrated in southwestern Ibaraki prefecture and in the Izu region. For the negative events (Fig. 2(b)), no such geographical concentration can be seen. In southwestern Ibaraki prefecture, the two types of focal mechanisms are mixed: shallower earthquakes with interplate motion between Kanto and the underthrusting PHS, and deeper interslab earthquakes between PHS and PAC. The focal mechanism in the Izu region includes both strike-slip and normal faulting.

As a simple indicator for relative activation or quiescence, we calculated the percentage of positive $\triangle \mathrm{CFF}$ val- 
Table 1. Number of earthquakes with positive/negative/insignificant or high absolute $\Delta$ CFFs as a function of threshold magnitudes.

\begin{tabular}{crrrr}
\hline Threshold magnitude & Positive $\Delta$ CFF & Negative $\Delta$ CFF & Insignificant or high absolute $\Delta$ CFF & Total number \\
\hline 1st nodal plane & & & & \\
\hline 2.0 & $18790(61.2 \%)$ & $5677(18.5 \%)$ & $6227(20.3 \%)$ & 30694 \\
2.5 & $11992(59.3 \%)$ & $3935(19.5 \%)$ & $4288(21.2 \%)$ & 20215 \\
3.0 & $5811(58.6 \%)$ & $2002(20.2 \%)$ & $8100(21.2 \%)$ & 4913 \\
3.5 & $2527(59.9 \%)$ & $873(20.7 \%)$ & $312(19.4 \%)$ & 1672 \\
4.0 & $995(59.5 \%)$ & $365(21.8 \%)$ & $108(17.4 \%)$ & 620 \\
4.5 & $354(57.1 \%)$ & $158(25.5 \%)$ & $28(16.7 \%)$ & 168 \\
5.0 & $90(53.6 \%)$ & $50(29.8 \%)$ & & 30694 \\
\hline 2nd nodal plane & & & $6016(19.6 \%)$ & 20215 \\
\hline 2.0 & $18828(61.3 \%)$ & $5850(19.1 \%)$ & $4233(20.9 \%)$ & 9913 \\
3.5 & $11771(58.2 \%)$ & $4211(20.8 \%)$ & $2133(21.5 \%)$ & 4219 \\
3.5 & $5638(56.9 \%)$ & $2142(21.6 \%)$ & $895(21.2 \%)$ & 1672 \\
4.0 & $2395(56.8 \%)$ & $929(22.0 \%)$ & $338(20.2 \%)$ & 620 \\
5.5 & $942(56.3 \%)$ & $392(23.4 \%)$ & $123(19.8 \%)$ & 168 \\
\hline
\end{tabular}

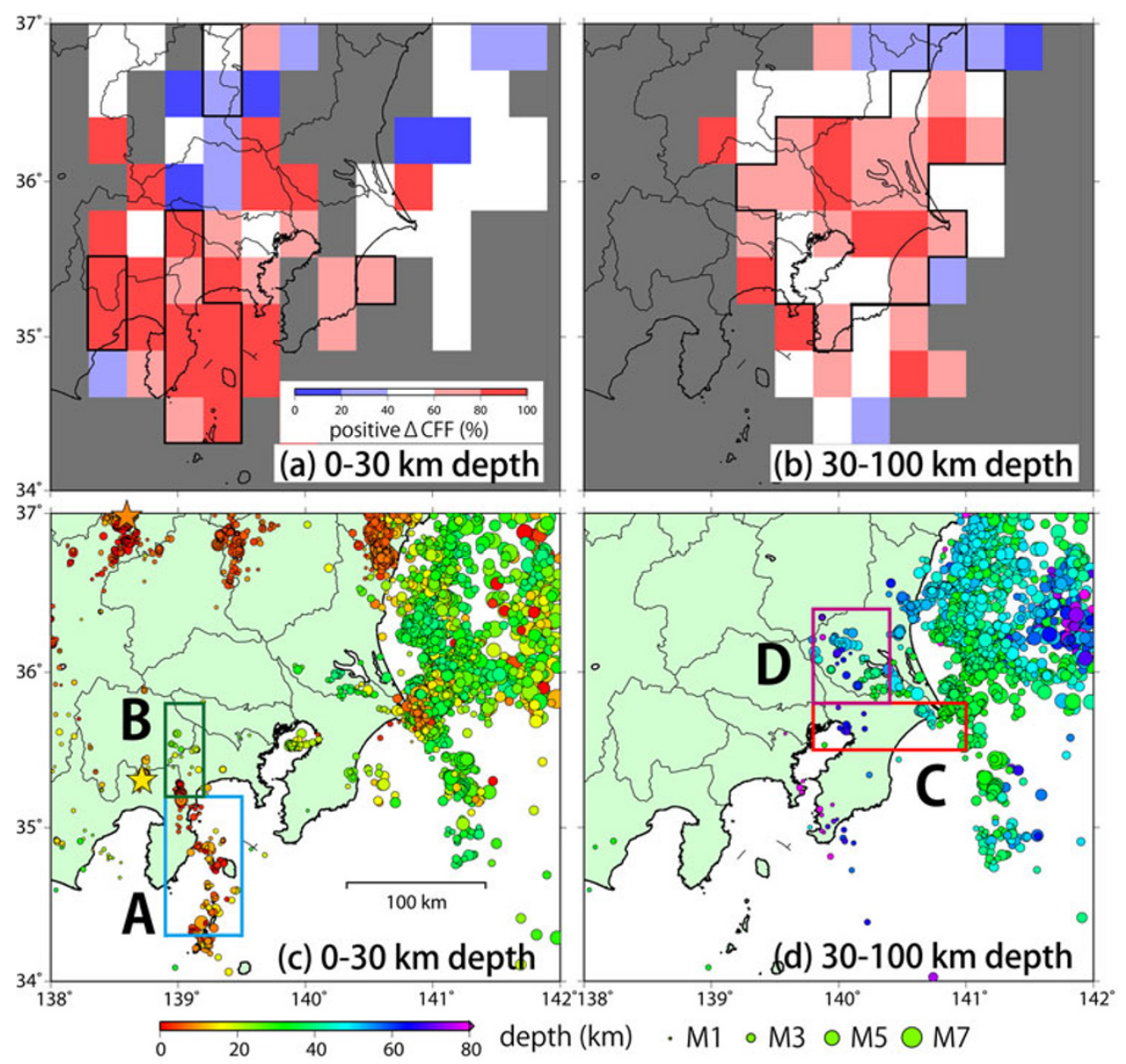

Fig. 3. (a) Percentage of earthquakes with positive $\triangle \mathrm{CFF}$ among all of the earthquakes with significant changes in each 0.3-degree grid square for a depth of 0 to $30 \mathrm{~km}$. The red (blue) regions are expected to be activated (deactivated) by the $\triangle \mathrm{CFF}$ due to the Tohoku-oki earthquake. The grid squares surrounded by thick lines indicate that more than 100 focal mechanism solutions are available. (b) Percentage for a depth of 30 to $100 \mathrm{~km}$. (c) Epicentral distribution during the three weeks after the mainshock $(M \geq 1.0$, depth $\leq 30 \mathrm{~km})$. The rectangular regions $(\mathrm{A}-\mathrm{D})$ indicate regions where the earthquakes were extracted for Fig. 4. (d) Epicentral distribution during the three weeks after the mainshock $(M \geq 1.0,30 \mathrm{~km}<$ depth $\leq$ $100 \mathrm{~km})$.

ues among all of the earthquakes with significant changes in each grid with 0.3-degree spacing (Fig. 3). If it is $0 \% / 100 \%$, the $\triangle \mathrm{CFF}$ for all of the earthquakes are negative/positive. If it is more than $50 \%$, the number of pos- itive $\triangle \mathrm{CFF}$ values is greater than the number of negative $\triangle \mathrm{CFF}$ values. When adequate focal mechanisms of past earthquakes are available, this indicates that the seismicity rate is expected to increase. 


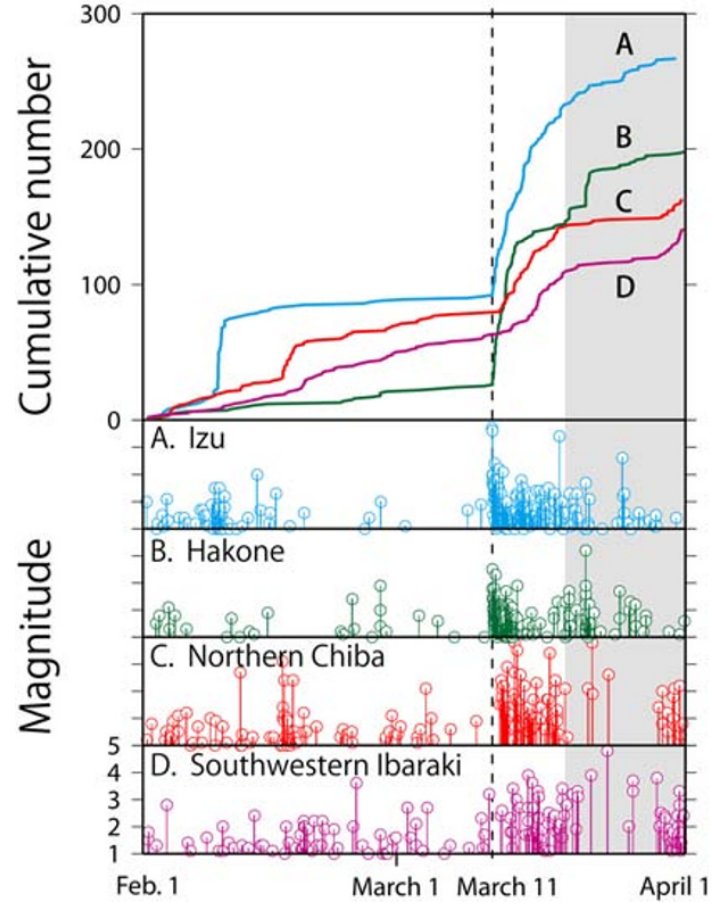

Fig. 4. Cumulative frequency curves and magnitude-time diagrams from February 1 to April 1 in the areas of (A) Izu, (B) Hakone, (C) northern Chiba prefecture, and (D) southwestern Ibaraki prefecture. The gray zone indicates possible intervals with a higher magnitude threshold.

Among the grid squares with a large number of focal mechanism solutions, we chose four areas (A, B, C, and D in Fig. 3) for verification of the predicted increase in seismicity. In all areas, the seismicity increase after the giant event is significant (Fig. 4). In the Izu region (area A), an active earthquake swarm took place in early February, while in northern Chiba prefecture (C), less active swarm-like activity occurred in the middle of the month. The increase in seismicity indicates that the seismicity rate changes in small earthquakes are fundamentally well-explained by the $\triangle \mathrm{CFF}$ due to the Tohoku-oki earthquake. The increase in seismicity implies an increase in the occurrence probability of large earthquakes in these areas. However, forecasting large induced earthquakes is not straightforward because large earthquakes are less frequent and the background stress levels for individual events are critical.

The correlation between a decrease in seismicity and areas with negative $\triangle \mathrm{CFF}$, called the "stress shadow", might be a topic of discussion. However, unlike seismicity increases, it is difficult to distinguish whether a decrease in seismicity is actual or artificial because the detection capability of small events may be lowered just after a great earthquake (e.g., Ogata and Katsura, 2006). The magnitude threshold in the PDE catalog is temporally higher, presumably because the determination of the hypocenters was delayed due to occurrences of a large number of earthquakes after March 11.

Earthquakes of a previously unknown type took place in northern Ibaraki prefecture. The focal mechanisms in this cluster are dominantly normal-type, with the $T$-axis in the E-W direction, presumably induced by the extension of the upper plate in the gigantic thrusting. Since earthquakes with this type of mechanism are not seen in the focal mechanism catalog of past events, our method cannot forecast them. The method used in this study is entirely based on the assumption that the focal mechanisms of past and future events are similar.

There are some other possible factors that may affect seismicity rate changes and/or occurrences of large earthquakes. The first is the contribution of dynamic stress changes (e.g., Hill et al., 1993; Anderson et al., 1994). The Izu and Hakone regions are sites of geothermal and recent volcanic activities, and the resulting dynamic stress changes might be important for earthquake triggering just after the mainshock. The second factor is pore pressure change. An acceleration of slip at the deeper plate boundary might cause excess fluid dehydration, affecting the seismicity in a tiny volume of the region studied. The third factor is the contribution of post-seismic slip along the plate boundary and large aftershocks, although the slip of aftershocks that occurred just after the mainshock is included.

Our results are based on a preliminary source model and the earthquake catalog. Various fault models based on the tsunami waveform, far-field body waves, strong motion seismographs, and others are now being proposed and updated. In addition, the progress of significant afterslip is suggested, based on GPS observation. The PDE catalog that was used for post-mainshock seismicity will be revised later. Therefore, the correlation between the $\triangle \mathrm{CFF}$ and changes in the seismicity rate should be re-examined using the final catalog and updated fault models. However, these would not affect the main results of this study.

\section{Concluding Remarks}

An increase in seismicity in the Kanto region after the Tohoku-oki earthquake was forecast on the basis of calculation of 30,694 static changes in the Coulomb Failure Function $(\triangle \mathrm{CFF})$. Almost 19,000 focal mechanisms of previous events in this region indicate a significant increase in $\triangle \mathrm{CFF}$ compared with less than 6,000 that indicate a significant decrease. However, the areas where active seismicity is predicted are mainly in the southwestern Ibaraki and northern Chiba prefectures, where intermediate-depth earthquakes occur, and in the shallow crustal areas of the Izu and Hakone regions. A comparison of seismicity before and after the giant event shows that our method successfully predicted the activation of seismicity.

Acknowledgments. We thank Drs. Ross S. Stein and Kei Katsumata who gave us thoughtful and relevant comments and suggestions to improve this paper, and Prof. Kiyoshi Yomogida for editing. We used a variable slip model of the 2011 off the Pacific coast of Tohoku Earthquake provided by Dr. Shinzaburo Ozawa of the Geospatial Information Authority of Japan, a preliminary determined earthquake catalog from JMA, and focal mechanisms provided by NIED. We also used the Generic Mapping Tools (Wessel and Smith, 1998) for drawing figures and the subroutine program by Okada (1992) for calculating $\triangle \mathrm{CFF}$. We thank all of these organizations and persons. This study was partially supported by the Observation and Research Program for Prediction of Earthquakes and Volcanic Eruptions, and the Special Project for Earthquake Disaster Mitigation in the Tokyo Metropolitan Area from the Ministry of Education, Culture, Sports, Science and Technology (MEXT) of Japan. 


\section{References}

Anderson, J. G., J. N. Brune, J. N. Louie, Y. Zeng, M. Savage, G. Yu, Q. Chen, and D. dePolo, Seismicity in the western Great Basin apparently triggered by the Landers, California, earthquake, 28 June 1992, Bull. Seismol. Soc. Am., 84, 863-891, 1994.

Earthquake Research Committee, Long-term Evaluation for Seismicity along the Sagami-Trough, 31 pp, 2004.

Hardebeck, J. L., J. J. Nazareth, and E. Hauksson, The static stress change triggering model: Constraints from two southern California aftershock sequences, J. Geophys. Res., 103(B10), 24427-24437, 1998.

Hill, D. P., P. A. Reasenberg, A. Michael, W. J. Arabaz, G. Beroza, D. Brumbaugh, J. N. Brune, R. Castro, S. Davis, D. dePolo, W. L. Ellsworth, J. Gomberg, S. Harmsen, L. House, S. M. Jackson, M. J. S. Johnston, L. Jones, R. Keller, S. Malone, L. Munguia, S. Nava, J. C. Pechmann, A. Sanford, R. W. Simpson, R. B. Smith, M. Stark, M. Stickney, A. Vidal, S. Walter, V. Wong, and J. Zollweg, Seismicity remotely triggered by the magnitude 7.3 Landers, California, Earthquake, Science, 260, 1617-1623, 1993.

Imanishi, K., Y. Kuwahara, T. Takeda, and Y. Haryu, The seismicity, fault structures, and stress field in the seismic gap adjacent to the 2004 MidNiigata earthquake inferred from seismological observations, Earth Planets Space, 58, 831-841, 2006.

Ishibe, T., A. Nishiyama, K. Satake, and K. Shimazaki, Review of previous studies on M7-class earthquakes that occurred in the southern Kanto region and data collection-The 1894 Meiji Tokyo earthquake and the 1895 Ibaraki-Ken Nanbu earthquake-, Bull. Earthq. Res. Inst. Univ. Tokyo, 84, 149-182, 2009a (in Japanese with English abstract).

Ishibe, T., A. Nishiyama, K. Satake, and K. Shimazaki, Review of previous studies on M7-class earthquakes that occurred in the southern Kanto region and data collection-The 1921 Ibaraki-Ken Nanbu earthquake, the 1922 Uraga-channel earthquake and the 1987 Chiba-Ken Toho-Oki earthquake-, Bull. Earthq. Res. Inst. Univ. Tokyo, 84, 183-212, 2009b (in Japanese with English abstract).

Ishibe, T., K. Shimazaki, H. Tsuruoka, Y. Yamanaka, and K. Satake, Correlation between Coulomb stress changes imparted by large historical strike-slip earthquakes and current seismicity in Japan, Earth Planets Space, 63, 301-314, 2011.

Matsumura, S. and Observation and Research Group of Crustal Activities in the Kanto-Tokai District, Focal mechanism solutions in the KantoTokai district over the past 20 years-Summary of observational results from the Special Research Project "Research on Seismic Activities in the Kanto-Tokai District" (Part 4)—, Tech. Note of the NIED, 224, 184, 2002.

Ogata, Y. and K. Katsura, Immediate and updated forecasting of aftershock hazard, Geophys. Res. Lett., 33, L10305, doi:10.1029/2006GL025888, 2006.

Okada, Y., Internal deformation due to shear and tensile faults in a half space, Bull. Seismol. Soc. Am., 82, 1018-1040, 1992.

Reasenberg, P. A. and R. W. Simpson, Response of regional seismicity to the static stress change produced by the Loma Prieta earthquake, Science, 255, 1687-1690, 1992.

Stein, R. S., G. C. P. King, and J. Lin, Change in failure stress on the southern San Andreas fault system caused by the 1992 magnitude $=7.4$ Landers Earthquake, Science, 258, 1328-1332, 1992.

Toda, S., R. S. Stein, P. A. Reasenberg, and J. H. Dieterich, Stress transferred by the Mw $=6.8$ Kobe, Japan, shock: Effect on aftershocks and future earthquake probabilities, J. Geophys. Res., 103, 24543-24565, 1998.

Toda, S., Coulomb stresses imparted by the 25 March $2007 M_{\mathrm{w}}=6.6$ Noto-Hanto, Japan, earthquake explain its 'butterfly' distribution of aftershocks and suggest a heightened seismic hazard, Earth Planets Space, 60, 1041-1046, 2008.

Tsuruoka, H., Development of seismicity analysis software on workstation, Tech. Res. Rep. ERI, Univ. Tokyo, 2, 34-42, 1998.

Wessel, P. and W. H. F. Smith, New, improved version of Generic Mapping Tools released, Eos Trans. AGU, 79(47), 579, 1998.

T. Ishibe (e-mail: ishibe@eri.u-tokyo.ac.jp), K. Shimazaki, K. Satake, and $\mathrm{H}$. Tsuruoka 